\title{
CORRESPONDENCE
}

\section{Screening of urinary tract infections by ELISA}

We were pleased to read the article by Gibb and Edmond.' Their results are in broad agreement with our evaluation of a commercially available enzyme linked immunosorbent assay (ELISA) (Uristat, Shield diagnostics, Dundee) for screening urinary tract infections in an elderly population. ${ }^{2}$

We note with interest, however, the authors' comment regarding the theoretical possibility of false positive results in patients with gonococcal and non-specific urethritis They postulate that this may result from inflammation of the urethral mucosa and subsequent leakage of unselected IgG antibodies from the serum into the urine.

In patients with gonococcal urethritis there is also the further possibility of cross-reaction between the lipopolysaccharide core (LPS core) antigen component of an assay and the specific antibodies produced against it. We investigated this problem using the Uristat assay. First, void specimens of urine were collected from 67 (41 men, 26 women) patients attending the genitourinary medicine clinic. All patients had signs and symptoms of urethritis, and had a leucocytic urethral exudate with the presence of four or more polymorphonuclear leucocytes per oilimmersion field ( $\times 1000$ magnification).

Each urine specimen $(20 \mathrm{ml})$ was collected in Boricon containers (Medical Wire and Equipment, Corsham, Wiltshire, England). The urine samples were cultured semiquantitavely on $10 \%(\mathrm{v} / \mathrm{v})$ horse blood agar and cysteine lactose electrolyte deficient (CLED) agar, and a pure growth of a single bacterial species of $>10^{5}$ organisms per $\mathrm{ml}$ taken as an indicator of significant bacteriuria. Each undiluted urine sample $(100 \mu \mathrm{l})$ was analysed, in duplicate, using the Uristat test, as described previously. ${ }^{2}$

Each assay plate also included high and low controls which were supplied by the manufacturers. All specimens were also tested for antibacterial activity by inoculating $100 \mu \mathrm{l}$ of urine on to an Isosensitest (Oxoid Ltd) plate seeded with a fully sensitive strain of Escherichia coli (NCTC 10418).

All urethral exudates were cultured for Neisseria gonorrhoeae. Swabs were inoculated in the clinic on to GC non-selective agar (Oxoid Ltd) and GC selective agar (Oxoid Ltd) containing LCAT (lincomycin, colistin, amphotericin B and trimethroprim) antibiotic supplement (Oxoid Ltd). Both media were supplemented with $5 \%(\mathrm{v} / \mathrm{v})$ lysed horse blood (Gibco Biocult Ltd). Chlamydia trachomatis was detected by direct immunofluorescence microscopy (Microtrak, Genetic Systems Corporation, Syva UK). All positive results were confirmed by ELISA using IDEIA (Boots Celltech Diagnostics Ltd).

Results of culture tests and Uristat assay are shown in the table. Eight patients were culture positive for $N$ gonorrhoeae, two for $C$ trachomatis, and four patients had a mixed infection with both organisms. Using the Uristat assay, there were no false positive results in urine specimens from patients with gonococcal and non-specific urethritis.
Results of culture tests and Uristat assay

\begin{tabular}{ll}
\hline Test & $\begin{array}{l}\text { Number (\%) of patients } \\
(n=66)\end{array}$ \\
\hline Urine: & \\
Significant bacteriuria & 0 \\
Uristat ELISA positive & 0 \\
Antibacterial activity & 0 \\
Urethral exudate: & \\
N gonorrhoeae positive & $8(12)$ \\
C trachomatis positive & $2(3)$ \\
N gonorrhoeae and & \\
C trachomatis positive & $4(6)$ \\
\hline
\end{tabular}

This may have been due to the fact that IgG antibodies that have leaked across the urethral mucosa are diluted out in the urine to a sufficiently low concentration, that is below the sensitivity threshold of this assay. Furthermore, the walls of the Uristat microtitre plates are coated with an antigenic mixture of six common urinary pathogens: $E$ coli, Proteus mirabilis, Klebsiella aerogenes, Staphylococcus saprophyticus, Pseudomonas aeruginosa and Citrobacter freundii. However, no details of the exact nature of the components of this antigenic mixture are provided by the manufacturer. It may well be that LPS core antigen is not a major antigenic component of this assay, and hence the lack of false positive results.

In conclusion, although recent publications $^{1 / 3}$ have reported that measurement of urinary antibodies by ELISA is not a useful method of screening urine samples before culture, there do not seem to be any false positive reactions in patients with urethritis when using theUristat assay.

$$
\begin{array}{r}
\text { B THAKKER } \\
\text { J R MICHIE } \\
\text { I B TAIT } \\
\text { A C McCARTNEY } \\
\text { Department of Microbiology, } \\
\text { Royal Infirmary, } \\
\text { Glasgow G4 OSF }
\end{array}
$$

1 Gibb A P, Edmond D M. Urinary IgG antibody against mixed heat-killed coliform antigen and lipopolysaccharide core antigen. $\mathcal{f}$ Clin Pathol 1992;45:161-4.

2 Michie JR, Thakker B, Bowman A, McCartney AC. Evaluation of enzyme linked immunosorbent assay for screening urinary tract infecbent assay for screening urinary tract infec-
tion in elderly people. $\mathcal{F}$ Clin Pathol 1992; tion in

3 MacGowan AP, Marshall JP, Cowling P, Reeves DS. Measurement of urinary lipopolysaccharide antibodies by ELISA as a screen for urinary tract infection. $f$ Clin Pathol 1991;44:61-3

Drs Gibb and Edmond comment:

We appreciate the response to our article from Thakker and colleagues. Their findings make a positive and interesting contribution to the debate.

They leave the anomaly that Gram positive urinary tract infections (UTI) result in the presence of antibodies to Gram negative bacteria in the urine, while gonococcal and chlamydial urethritis does not result in the presence of antibody to the mixture of Gram negative and Gram positive bacteria in the Uristat test. Differences in the antigens involved may be important, but this seems unlikely as LPS core epitopes are probably exposed in the Uristat test just as they were in our mixed heat-killed coliform antigen. The difference may be due to the much greater area of urothelium which is inflamed in UTI, resulting in a the non-specific leakage of more antibody into the urine.

Assays of total IgG in the urine in UTI and in urethritis are required to clarify this point. We are in the process of measuring IgG in urine in suspected UTI, but unfortunately no samples from patients with urethritis are currently available (the samples reported by Thakker et al have not been kept). We can find no reference in published findings which reports urinary immunoglobulin titres in urethritis.

\section{The action of vitamin $B_{12}$}

Dr Chanarin and his colleagues review in some detail the evidence against the methyl folate trap hypothesis and that in favour of their own folate starvation hypothesis on the action of vitamin $B_{12}$ on folate metabolism. Both hypotheses are based on the methylcobalamin dependent methionine synthetase reaction.

In this, homocysteine reacts with 5-methyltetrahydrofolate to form methionine and tetrahydrofolate $\left(\mathrm{H}_{4}\right.$ folate). In the one hypothesis, methionine derived from this reaction is regarded as an important precursor of formate, required as formaltetrahydrofolate for folate polyglutamate synthesis In the other, the liberated $\mathrm{H}_{4}$ folate is made available for the synthesis of all the single carbon atom folate compounds which are finally polyglutamated to form the active folate coenzymes. According to both hypotheses, therefore, all the latter are in short supply in vitamin $B_{12}$ deficiency. Of these the most important is 5,10 -methylene tetrahydrofolate $\left(5,10-\mathrm{CH}_{2}-\mathrm{H}_{4}\right.$ folate) the folic acid coenzyme active in the thymidylate synthetase reaction, impairment of which is regarded as the biochemical basis of megaloblastosis.

I would like to suggest that vitamin $B_{12}$ has an additional action which is independent of both the thymidylate synthetase and the methionine synthetase reactions. Two independent lines of investigation support this view.

First, folic acid is very much more effective than vitamin $B_{12}$ in correcting the deoxyuridine suppression test (dU test) - a test specifically designed to measure the activity of the thymidylate synthetase reaction. In one series $5 \mu \mathrm{g} / \mathrm{ml}$ of folic acid was almost as effective as $100 \mu \mathrm{g} / \mathrm{m}$ of vitamin $B_{12}$ in correcting the test in vitamin $B_{12}$ deficient marrow. ${ }^{2}$ In vivo, however, vitamin $B_{12}$ in doses of $2 \mu \mathrm{g}$ per day produced a reticulocyte response in pernicious anaemia, but folic acid in doses of $200 \mu \mathrm{g}$ per day failed to do so. ${ }^{34}$ Given the weight for weight approximation of such comparisons, this huge discrepancy is still strong evidence that vitamin $B_{12}$ in man has an action other than that of correcting the thymidylate synthetase reaction.

Secondly, pharmacological doses of $200 \mu \mathrm{g}$ of vitamin $B_{12}$ a day promptly increased the low pretreatment serum methionine concentration to normal in three days in cases of pernicious anaemia. ${ }^{5}$ Vitamin $B_{12}$ in physiological doses of $2 \mu \mathrm{g} /$ day not only failed to do this but actually depressed it 
to extremely low concentrations and the hypomethioninaemia persisted for several days (unpublished observation). A possible explanation for this unexpected result lies in the fact that methionine metabolism is influenced, and in opposite directions, by both methylcobalamin and by adenosylcobalamin, the former through the methionine synthetase reaction which increases the serum methionine. The latter is a coenzyme in the methylmalonyl-CoA mutase reaction; this is the last reaction in the propionyl-CoA-succinyl CoA pathway along which methionine is catabolised to the citric acid cycle. Adenosylcobalamin, therefore, aids the catabolism of methionine and depresses its concentration in serum. The above findings suggest that adenosylcobalamin alone is active and that the action of methylcobalamin is not expressed, and the methionine synthetase reaction therefore not activated by these very minute doses of vitamin $B_{12}$. They do, however, invariably produce a reticulocyte response, often a very brisk one, which again suggests that vitamin $B_{12}$ has an erythropoietic action which is independent of the methionine synthetase reaction, and by inference, from both the methylfolate trap and the formate starvation hypothesis, in the absence of the thymidylate synthetase action as well.

Unfortunately by the time the possible importance of these results was realised the work could not be repeated. If, however, the above interpretation is correct it would probably take several days for these very small doses of vitamin $B_{12}$ to correct the $d U$ suppression test. This contention could therefore readily be tested by relating this interval to the daily reticulocyte count following a daily dose of $2 \mu \mathrm{g}$ of vitamin $\mathrm{B}_{12}$ in pernicious anaemia. A clear reticulocyte response, not necessarily the peak, occurring before the $\mathrm{dU}$ test is corrected would lend it support.

T E PARRY Awelon, Pen-y-Turnpike, South Glamorgan CF6 4 HG

1 Chanerin I, Deacon R, Lumb M, Perry J Cobalamin and Folate, recent developments. f Clin Pathol 1992;45:277-83.

2 Ganeshaguru K, Hoffbrand AV. The effect of deoxyuridine, vitamin $B_{12}$ folate and alcohol
on the uptake of thymidine and on the on the uptake of thymidine and on the
deoxymucleoside triphosphate concentration in normal and megaloblastic cells. $\mathrm{Br} \mathcal{F}$ of in normal and megalobl

3 Hans HA, Weinfeld A. Metabolite effect and diagnostic value of small doses of folic acid and vitamin $B_{12}$ in megaloblastic anaemia. Acta Medica Scandinavia 1962; 172:427-42.

4 Chanarin I. Megaloblastic anaemia. Clin Hae matol 1976;5:754.

5 Parry TE. Serum valine and methionine levels in pernicious anaemia under treatment. $\mathrm{Br} f$ Haematol 1969;16:271-9.

\section{Risk of inhaling cyanide during necropsy examination}

I read with interest the article by Forrest, Galloway, and Slater on the risk of inhaling cyanide during necropsy on cases of cyanide poisoning.' There is, admittedly, a theoretical risk of inhaling a large amount of cyanide, as observed by Andrews et al. ${ }^{2}$

The recommendation that a respirator be worn during the necropsy or that the stomach should be opened in a fume cabinet is commendable but suffers from one draw- back. In one of my cases the diagnosis of cyanide poisoning was made only after opening the stomach. ${ }^{3}$ This case presented as a sudden natural death and my diagnosis of cyanide poisoning, based solely on the smell, was greeted with considerable disbelief by the investigating police officers. Subsequent investigations led to the discovery of a suicide note and an empty container but the impression of everybody concerned, including myself, was that of sudden natural death. At least I am fortunate that I can smell cyanide (My colleague at that time has never been able to).

Theoretically, then, a pathologist who could not smell cyanide would inhale potentially dangerous amounts of cyanide during such a necropsy. Should pathologists routinely wear respirators when performing any necropsy where the circumstances of death are not clear? Or should they routinely open the stomach in a fume cabinet in all such cases? When we refer to the changing face of pathology is it because pathologists of the future will be wearing gas masks? Perhaps readers should be told.

$$
\begin{array}{r}
\text { G C A FERNANDO } \\
\text { Central Pathology Laboratory, } \\
\text { Histopathology Department, } \\
\text { North Staffordshire Hospital Centre, } \\
\text { Hartshill, Stoke on Trent ST4 7PA }
\end{array}
$$

1 Forrest ARW, Galloway JH, Slater DN. The cyanide poisoning necropsy: An appraisal of risk factors. I Clin Pathol 1992;45:544-5.

2 Andrews JM, Sweeney ES, Grey TC, Wetzel T.

The biohazard potential of cyanide poisoning during post-mortem examination. $\mathcal{f}$ For $S_{c i}$ 1989;34:1280-4.

3 Fernando GCA, Busuttil A. Cyanide ingestioncase studies of four suicides. Am $\mathcal{f}$ Forens Med Pathol 1991;12:241-6.

\section{Drs Forrest, Galloway, and Slater comment:}

We are confident that either common sense or natural selection would prevail in the situation Dr Fernando describes. Pathologists will make a sensible judgement of the risks in a particular case and the precautions that reasonably ought to be taken in the light of all the circumstances, including their knowledge of their own olfactory capabilities.

\section{Glove puncture in the post mortem room}

I cannot allow Drs Weston and Locker's comments on my criticism of their paper to go unchallenged. They have not correctly cited the paper of Hall et al.' This study involved 664 technicians (588 anatomical pathology technicians and 76 mortuary technicians), not 76 as they claim, plus 774 consultants. It also included a control group of Coroner's officers. Two cases of hepatitis B were indeed reported as Drs Weston and Locker state. However, one of these was in a Coroner's officer and therefore unlikely to be due to unnoticed glove puncture! The incidence in the at risk and control groups was therefore equal. The one reported case of tuberculosis is almost certainly unrelated to glove puncture. The discussion at the end of the paper concludes that apart from the expected high rates of respiratory disorders, the digestive and infectious disease excess noted in the technicians was similar to the findings of a large scale survey of medical laboratory workers. I would therefore reiterate my conclusion that unnoticed glove puncture is not in itself a health hazard. Laceration of the skin is undoubtedly a health hazard but is not likely to be affected by more frequent glove changes. I agree with the other correspondents that the efforts to minimise the risk of blood born infection in the post mortem room would be better directed towards reducing that hazard. I have found that the available chain mail protective overgloves for the left hand are of great value in this respect.

$$
\begin{array}{r}
\text { P J DUNN } \\
\text { Department of Pathology, } \\
\text { Royal Infirmary, } \\
\text { Castle Street, } \\
\text { Worcester WR1 } 3 A S
\end{array}
$$

1 Hall AJ, Aw TL, Harrington JM. Morbidity survey of post mortem room staff. $\mathcal{f}$ Clin Pathol 1991;44:433-5.

c-erb-B-2 expression in male breast carcinoma

Fox et al recently reported a complete lack of c-erb-B-2 expression in 21 cases of male breast carcinoma, ${ }^{1}$ while Wright et al reported overexpression in a single case. ${ }^{2}$ We have so far examined 33 cases of male breast carcinoma for $c$-erb-B-2 expression using the monoclonal antibody NCL-CB11 (Novocastra) and a standard immunoperoxidase technique. Omission of the primary antibody and a known positive case of female breast carcinoma were used as negative and positive controls, respectively. Membrane staining was completely absent in 20 cases, but positive membrane staining was present focally within the tumour in 12 cases and throughout the tumour in one case. Thus $39 \%$ of our cases show evidence of c-erb-B-2 overexpression. This figure is similar to the $35 \%$ reported by Gattuso et $a l^{3}$ in their series of 26 cases.

Our results show that a proportion of male breast carcinomas are associated with c-erbB-2 overexpression, which is usually related to gene amplification. However, it remains to be seen whether this has the same prognostic importance as that seen in female breast carcinomas.

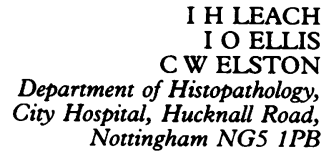

Fox SB, Day CA, Rogers S. Lack of $c-e r b-B-2$ oncoprotein expression in male breast carcinoma. I Clin Pathol 1991;44:960-1.

2 Wright C, Prasad K, Lennard TJW. erbB2 expression in breast and other human expression in breast and other hum
mours. $\mathcal{F}$ Clin Pathol 1992;45:459-60.

3 Gattuso P, Reddy V, Green L, Castelli M, Wick $M$. "New" prognostic factors in invasive M. "New" prognostic factors in invasive
breast cancer in men. Mod Pathol 1992;5: 13A.

\section{The teaching of death certification}

Death certificates are usually issued by preregistration house officers, often badly, and sometimes with only a mode of death as opposed to the disease producing death.' 